\title{
Regional employment impacts of marine energy in the Scottish economy:
}

\section{A general equilibrium approach}

\author{
Michelle Gilmartin* and Grant Allan ${ }^{+}$ \\ ${ }^{*}$ Division of Economics, University of Stirling \\ ${ }^{+}$Fraser of Allander Institute, Department of Economics, University of Strathclyde
}

Published in Regional Studies, 2014, available online 21 ${ }^{\text {st }}$ August 2014, link here:

http://www.tandfonline.com/doi/full/10.1080/00343404.2014.933797\#.U s XMVdXiA

\begin{abstract}
One aspect of the case for policy support for renewable energy developments is the wider economic benefits that are expected to be generated. Within Scotland, as with other regions of the UK, there is a focus on encouraging domestically-based renewable technologies. In this paper, we use a regional computable general equilibrium framework to model the impact on the Scottish economy of expenditures relating to marine energy installations. The results illustrate the potential for (considerable) 'legacy' effects after expenditures cease. In identifying the specific sectoral expenditures with the largest impact on (lifetime) regional employment, this approach offers important policy guidance.
\end{abstract}

Keywords: Marine energy; regional economic impacts; Scottish economy JEL classification: C68; R11; R58 


\section{Introduction}

Reducing global greenhouse gas emissions to safe and sustainable levels is expected to require expenditures of around 2\% of global GDP per year (Stern, 2006, 2008). It is anticipated that these will be offset to some extent (and possibly outweighed by) global economic benefits associated with better energy security, improved air quality, and new employment in 'green' industries. At a regional level in the UK, the Scottish government has placed particular emphasis on the economic development 'dividend' associated with investments in renewables (Scottish Government, 2009). Expenditures on the manufacture, installation and maintenance of renewables devices are expected to have positive local economic impacts, including employment creation. In this paper, we examine the link between investments in renewable energy capacity and regional economic (particularly employment) change.

Although there are a (limited) number of studies which attempt to quantify such impacts in the UK (see Section 2), there is a significant degree of uncertainty over the estimates. This is reflected in, for example, a lack of consistency and transparency in estimation methodologies, and a wide dispersion of results across studies. Furthermore, there is a lack of system-wide analyses in the literature. This is an important omission if crowding out and supply-side adjustments are anticipated effects of regional demand-side stimuli. For example, a demand stimulus might increase wages and reduce a region's competitiveness, mitigating the positive 
impacts of the demand increase and potentially crowding out activity in some sectors. Additionally, regional in-migration of labour supply in response to higher wages could ease labour market pressures, and lead to further changes in regional supply-side dynamics. Where changes in the supply-side do occur, these can generate 'legacy' effects: economic impacts beyond the period in which the expenditures occur (Allan et al., 2008). Capturing these could be important for the exante evaluation of renewable energy investments. Thus analyses which (implicitly) assume a passive supply side, or focus solely on the period of demand expenditures, could misrepresent the actual qualitative and/or quantitative response to regional policy.

In this paper we adopt an economy-wide modelling approach for examining the link between expenditure on renewable (specifically marine) energy developments and regional employment change. We use a multi-sectoral computable general equilibrium (CGE) model of Scotland to quantify the impact on economic activity of energy capacity expenditures. We compare results from our economy-wide modelling to those of the Scottish government's Marine Energy Group, who also quantify the employment impacts associated with marine energy expenditures, but following a different methodology (which is not economy-wide and which implicitly assumes a passive supply side), and also to those of a conventional Input-Output (IO) system, which typically does not explicitly model supply-side interactions. 
The overall objective of this paper is to provide a better contribution to regional policy makers' knowledge base on the economic impact of renewables expenditures than that currently available in the literature. Our methodology allows us to consider a number of as yet unexplored issues. Firstly, we identify the mechanisms through which renewables expenditures drive employment change at the regional level. Secondly, we demonstrate the importance of the supply-side of the regional economy in transmitting the demand stimulus through the wider economy and over time. Thirdly, we identify those expenditures at the sectoral level which have the largest employment-creation impact (an important concern of policy makers looking to develop high-value supply chains in the renewables industry). In doing so, our analysis emphasises, within the context of an issue currently of great interest to regional policy makers, the potential added value of a general equilibrium approach to regional policy analysis, over and above a partial equilibrium approach, of the kind currently used by the Scottish government's Marine Energy Group.

The Scottish case for renewables as a regional development policy is particularly interesting for a number of reasons. Firstly, the dispersion of renewables resources across the UK suggests that a disproportionately large amount of renewables industry activity will be concentrated in Scotland, particularly for marine energy $^{1}$. Secondly, although energy policy is strictly a reserved power ${ }^{2}$, the Scottish

\footnotetext{
${ }^{1}$ For example, in Scotland the Pentland Firth area alone contains around 50\% of the UK tidal resource and around 25\% of the European resource (Department for Business Enterprise and Regulatory Reform, 2008).
} 
government and Parliament have nevertheless interpreted the devolved aspects of energy policy widely enough to develop a distinctive energy policy influence. This includes the setting of separate targets for renewable energy generation that are more progressive than those of the UK government ${ }^{3}$, and the vetoing of new nuclear energy developments. Accordingly, there is a well-articulated debate about the role of the renewables industry in Scotland and its potential economic impacts. Thirdly, the active discussion among policy makers is accompanied by detailed government and private sector information on, for example: resource estimates for Scotland; timescales for technology installations; and device cost estimates, including the sectoral breakdown of expenditures. This allows for well-informed assumptions to underpin our economic analysis.

In this paper we proceed as follows. In Section 2 we describe the literature on the regional employment impacts of renewable energy expenditures and consider the results and methodology of the Scottish Government's Marine Energy Group study of the employment effects of marine renewables expenditures. In Section 3 we

\footnotetext{
${ }^{2}$ Energy policy, and the key policy instruments that can influence the energy industry (i.e. taxation and regulation) remain reserved powers for the UK government. Within energy policy, the Scottish government has responsibility only for the promotion of renewable energy and energy efficiency, and the Scottish Parliament currently has no power to vary taxes, other than the ability to vary the standard rate of income tax by up to $3 p$ in each pound. Devolved planning powers also allow for energy developments (e.g. nuclear) to be vetoed.

${ }^{3}$ The Scottish Government has set a target for at least 30\% of Scottish energy demand to be sourced from renewables by 2020 , with $100 \%$ of electricity consumption to be met by renewables generation in 2020 (Scottish Government, 2011). In contrast, the UK target is for $15 \%$ of energy demand to be sourced from renewables (European Parliament, 2009), and the UK Government's Renewables Energy Strategy suggests that by 2020 around $30 \%$ or more of UK electricity consumption could come from renewable sources by 2020 (though this has not been announced as an explicit target) (Department for Energy and Climate Change, 2011).
} 
argue that linking renewable energy expenditures to economic impacts requires a more comprehensive and transparent modelling approach than that adopted in the current literature, and that a regional CGE model is a particularly useful framework for such an analysis. We also describe the AMOS CGE model of Scotland and our simulation strategy. In Section 4 we present the results of our simulations and compare these to those of the S\&I (2009) analysis, as well as expenditure impacts estimated using a simple IO methodology. In Section 5 we discuss the importance of locally retained expenditures to the findings, and in Section 6 we conclude.

\section{Renewable energy expenditures and regional employment change}

\section{$2.1 \quad$ Literature}

The (albeit limited) literature on the employment effects of marine energy developments reports a very wide range of estimates. The incumbent nature of the marine energy industry means that cost estimates, policy support mechanisms etc. change often, so that the underlying assumptions of individual estimates likely differ. Furthermore, such assumptions are often not clearly reported, making it difficult to compare and evaluate results. Additionally, the studies often do not detail the exact methodological approach which underlines the employment 
estimates $^{4}$. Consequently, it is difficult to examine how the marine energy developments are translated and quantified into economic changes; whether indirect and induced effects are considered; or whether crowding out and labour substitution are taken into account, for example. In this section, we consider the methodology and results of some estimates of the employment effects of renewables expenditures (particularly those of S\&I (2009), in Section 2.2). In Sections 3 and 4 we adopt the same deployment and expenditure stimulus as in S\&I (2009), but demonstrate how standard techniques can be used to more comprehensively evaluate the economic impacts of developments in the renewable energy sector compared to those in the existing literature.

The Carbon Trust (2011) estimates job creation in wave and tidal energy industries for the UK as a whole, and suggests that by 2050 there could be over $48,000 \mathrm{UK}$ jobs in the wave industry and around 20,000 in the tidal stream industry (according to a 'high' scenario). This is based on an installed capacity of marine technologies of around 27.5 GW by 2050. Underlying these estimates, the authors assume that: substantial innovation takes place in marine technologies (though it is not clear whether 'learning effects' are explicitly modelled); peripheral barriers to marine energy deployment are overcome (such as public acceptance and supply chain and grid infrastructure constraints); and significant export demand for UKmanufactured devices and technologies exists.

\footnotetext{
${ }^{4}$ With the exception of the Arthur D. Little (2005) study, where the authors explain that they calculate a 'rule of thumb' employment estimate of 1 job per MW of installed capacity based on questionnaire responses from a selection of UK wave energy developers.
} 
In Scotland, the Forum for Renewable Energy and Development (FREDS) (2004) reports that $1,300 \mathrm{MW}$ of marine energy installations in Scotland by 2020 should create 7,000 direct jobs in Scotland. AEA Technology and Poyry Energy Consulting $(2006,2007)$ estimate that marine energy installations in Scotland of 650MW by 2020 would lead to a 'net' jobs boost of 2,340 in Scotland, while a 330MW scenario projects 630 'net' jobs in Scotland. The authors assume that policy support mechanisms for the renewables industry exist. The 'net' impacts are based on the assumption that the job increases will be offset to some extent by job losses elsewhere that result from the renewables developments. The total gross (i.e. direct, indirect and induced) impact $^{5}$ on jobs in Scotland from marine development (without subtracting these lost jobs) of the 650MW scenario is 4,660 .

The Marine Institute and Sustainable Energy Ireland (2005) considers scenarios for the development of marine energy in Ireland, and suggests a total employment impact of 1,900 jobs based on 200MW of capacity installation. This estimate includes the impact of employment gains associated with the export of marine technologies developed in Ireland. At a sub-regional level, a study by Arthur D. Little (2005) estimates that the 'wave-hub' development in Cornwall in the South West region could generate 100 direct jobs, based on $20 \mathrm{MW}$ of installed capacity.

\footnotetext{
${ }^{5}$ For a given change in final demand for a sector, there will be a corresponding change in sectoral output. This change in sectoral output is the "direct" effect of the change in final demand. For an increase in sectoral outputs, there will be a corresponding change in demand and output in other sectors who supply intermediate inputs to that sector (and so on along the supply chain). This is the "indirect" effect. Additionally. households' income may be affected by such direct and indirect effects. A proportion of this income change may be spent (assuming an income increase) on final goods and services, This is the "induced" effect.
} 
The report suggests that the indirect job benefit could be significant at 450 jobs, with $20-40 \%$ of these retained in Cornwall, and more in the wider region.

\subsection{Sgurr and IPA energy report}

In Sgurr Energy and IPA (2009) (hereafter, S\&I, 2009), prepared for the Scottish government's Marine Energy Group, the authors attempt to quantify the potential economic (including employment) effects of renewable energy expenditures.

The report considers three scenarios for marine energy capacity in Scotland over the period 2010 to 2020 , in which a total of around 500MW, 1000MW and 2000MW of capacity is installed ('downside', 'base case' and 'stretch' scenarios, respectively), and estimates the total (global) expenditure and employment effects corresponding with these scenarios. The expenditures included are those costs prior to the operational and decommissioning phases of the marine device lifecycles, estimated using survey responses from marine energy developers. The cost of each MW declines over time in each scenario, consistent with 'learning' effects that reduce capital costs as technologies mature. Table 1a provides the capacity and total expenditure figures (both annual and cumulative) for each of the three scenarios. Monetary values are measured in 2009 prices. Demand and technology assumptions remain constant over each scenario. 
[Table 1a]

S\&I (2009) assume that the total expenditure that occurs in Scotland in each scenario is:

$$
E x_{t}^{S}=E x_{t}^{W} \alpha
$$

Equation 1

where $E x^{S}$ is the total expenditure in Scotland, $E x^{W}$ is the total worldwide expenditure, $t$ is the year and $\alpha$ represents the share of the total worldwide marine installation expenditures which is spent in the Scottish economy. Parameter $\alpha$ is assumed to be constant over time ${ }^{6}$ and across the scenarios ${ }^{7}$. Based on their consultation responses, S\&I (2009) use a value of $\alpha=0.53$. Accordingly, in the base case scenario, cumulative capacity is $991 \mathrm{MW}$ by 2020 , with an associated cumulative global expenditure of $£ 2.38$ billion. Of this, $£ 1.26$ billion is retained in Scotland.

Retained employment $\left(E m_{t}^{S}\right)$ is assumed to be:

\footnotetext{
${ }^{6}$ This implies that the Scottish marine energy industry does not become more competitive in marine installations over time, and that there are no 'home market effects' of the type popularised by Krugman (1980) and which are thought to underlie the success of the Danish export market in wind power technologies (Krohn, 1998; Sovacool, 2009), for example.

7 This share of local sourcing varies across the expenditure categories, however. We investigate the sectoral distribution of the expenditures and sectoral impacts in Sections 4.2 and 5.
} 


$$
E m_{t}^{S}=c_{t} \gamma \alpha
$$

Equation 2

where $c_{t}$ is the (incremental) capacity (in MW) installed in Scotland in year $t$, and $\gamma$ is the number of (worldwide) jobs supported by each MW.

The values of $c_{t}$ are based on S\&I's (2009) deployment scenarios for Scotland (Table 1a). The authors use an ad hoc method to estimate parameter $\gamma$. S\&I (2009) assume that each MW of marine energy capacity creates a total of $\gamma=20$ jobs in that year, across the world ${ }^{8}$ (held constant over 2012-2020). Using this methodology, S\&I (2009) estimate Scottish retained expenditure and employment impacts during 20102020b (Table 1b).

\section{[Table 1b]}

S\&I (2009) report the employment results as the 'direct' effect on Scottish employment. The report does not quantify the 'indirect' or 'induced' effects of the demand stimulus.

\footnotetext{
${ }^{8}$ This estimate is partly based on average consultation responses from developers asked about job creation prospects, and partly influenced by a review of the (scarce) literature.
} 
In the following sections, we use a general equilibrium regional economic modelling approach as a means of more formally capturing the link between marine energy expenditures and regional employment change. This is a more compelling approach to assessing likely employment impacts in that it is based on a theoryconsistent model that has been calibrated on a comprehensive database for the Scottish economy which incorporates all inter-industry linkages. In doing so, the methodology effectively captures the 'direct', 'indirect' and 'induced' effects associated with the demand stimulus.

\section{A modelling approach}

\subsection{Regional multi-sectoral models}

Two modelling methodologies are particularly useful for analysing the link between expenditures and regional economic impacts: conventional demand-driven IO and CGE modelling. Both are system-wide multi-sectoral frameworks, widely applied for regional analysis (Loveridge, 2004). These system-wide models allow for the relationships between all parts of the economic system to be captured, and can coherently link disturbances in one area of the regional economy (i.e. increased demands for the output for some sectors) to impacts across the economy. Multisectoral models are especially useful as these reveal the sectoral (as well as aggregate) distribution of changes in activity. 
IO modelling is typically configured as a demand-driven system (Miller and Blair, 2009) whereby changes in demand for particular sectors can cause changes in aggregate output via 'multiplier' effects. Type 1 multipliers measure the marginal effects on regional activity following a demand shock via the interaction of intersectoral links arising from intermediate inputs (as given by the IO table). By endogenising household incomes and expenditures, Type 2 multipliers also include the additional impact of changes in household consumption on the level of regional economic activity ${ }^{9}$.

Two key characteristics associated with IO models are relevant to our analysis in this paper. Firstly, the method assumes that there is excess capacity and involuntary unemployment such that the supply side adjusts passively to any demand change without pressure on wages or prices ${ }^{10}$. Secondly, there are fixed technical coefficients between each sector's purchase of inputs and its outputs: production thus operates under constant returns to scale ${ }^{11}$. As such, we might consider IO as a special case of a more general multi-sectoral model with these assumptions imposed.

A CGE methodology offers a more flexible model structure for analysing regional economic issues. The basic premise of a CGE model is a Walrasian general

\footnotetext{
9 Type 1 multipliers sum together the direct and indirect effects defined in footnote 5; Type 2 multipliers sum together the direct, indirect and induced effects.

${ }^{10}$ This would be consistent with an assumption that the relative prices of inputs remain constant in the event of a demand disturbance (McGregor et al., 1996).

${ }^{11}$ An early discussion of these two properties of IO models is provided in Ghosh (1958). Miller and Blair (2009) provide a more recent textbook treatment of the foundations and fundamental relationships of IO models.
} 
equilibrium (Walras, 1926). Typically (and in the case of the model we adopt in this paper), the model comprises (i) a detailed database of economy-wide data (such as an IO table or social accounting matrix (SAM)), which captures interdependencies between sectors at a particular point in time, and (ii) a set of equations describing model variables. These tend to be neoclassical in sprit (e.g. households maximise utility subject to a budget constraint; firms profit maximise), though often with some non-market clearing characteristics (such as unemployment) incorporated (see Section 3.2 for a specific description of the key AMOS model equations).

The more flexible nature of the CGE framework can allow the strict IO model assumptions of fixed technical coefficients and no supply constraints to be relaxed, and for the model to capture important aspects of regional economy responses to policy or other exogenous change. For example, CGE models can allow for labour and capital to be scarce resources in the short run, so that a demand stimulus puts upward pressure on wages and prices, resulting in a loss of regional competitiveness. Further, changes in the relative price of inputs (e.g. labour and capital) inputs can alter the optimal input mix for producers. In a regional context, the supply of labour can vary through interregional migration, in response to, for example, relative unemployment or wage rate differences across regional boundaries. 
The model used in this paper is AMOS (Harrigan et al., 1991): a CGE model of the Scottish economy ${ }^{12}$. Variants of this AMOS framework have been used in a number of applications (in particular related to regional economic issues). These include, for example, assessing regional policy spillovers (Gilmartin et. al., 2013); evaluating regions' responsibility for carbon emissions (Turner et al., 2012); and measuring the economic impact of an increase in energy efficiency (Hanley et al., 2009).

The AMOS model is calibrated on a SAM for Scotland for 2006. In this application, the AMOS model has twenty five commodities/sectors. The sectors identified include those in which the expenditures associated with the assessment, construction and installation of marine energy devices, as identified by S\&I (2009), are likely to be made. The twenty-five sectors are listed in Appendix A. The model has three transactor groups - households, government and corporations - and two exogenous transactors - the rest of the UK and rest of the world. Commodity markets are assumed to be competitive. Financial flows are not explicitly modelled, and the interest rate is assumed to be exogenous.

\footnotetext{
${ }^{12}$ AMOS is an acronym for $A$ Macro-micro Model Of Scotland. The model is calibrated using a Social Accounting Matrix based around the 2004 Scottish IO tables, rolled forward to 2006 (Scottish Government, 2007). The AMOS framework was originally designed for the Scottish economy, though variants of the model have been parameterised on data for other countries and regions, for example the UK (e.g. Gilmartin et al., 2013) and Greece (Pappas, 2008), and used for simulation applications for these economies.
} 
The AMOS framework allows a degree of flexibility in the choice of key parameter values and model closures. A constant feature of the model is that producers are assumed to minimise costs using a nested multi-level production function. Local intermediate inputs combine with rest of the UK and rest of the world imports via an Armington link (Armington, 1969) and the composite intermediate good is combined with a value added composite to produce sectoral gross output. Labour and capital combine in the production of value added in each sector. The AMOS framework allows for differing production functions to be employed, however in this application a CES specification is employed at each level of the production hierarchy for each sector. There are four components of final demand: consumption, investment, government consumption and exports. Of these, total household consumption is a linear function of real disposable income. Households' consumption of each sector's output depends on the relative prices of domestic and imported sectoral products, with a constant elasticity of substitution permitting households to substitute between domestic and non-domestically produced goods. Government consumption is assumed to be exogenous. Exports (and imports) are determined via an Armington link (Armington, 1969) and are therefore sensitive to relative prices. The specification of investment demand and capital are discussed below. Capital, inputs of labour and materials, constitute the supply side of the model. 
We impose a single Scottish labour market with perfect sectoral mobility (so workers can move between employment in different sectors). We assume that wages are subject to an econometrically parameterised regional bargaining real wage function (Layard et al., 1991) ${ }^{13}$. Under this configuration, the regional real consumption wage is directly related to workers' bargaining power and inversely related to the regional unemployment rate:

$$
\ln \left(\frac{w}{c p i}\right)=c-1.113 \ln (u)
$$

Equation 3

where $w$ is the Scottish nominal wage, $u$ is the Scottish unemployment rate, cpi is the Scottish consumer price index and $c$ is a calibrated parameter which ensures that the model replicates the assumed steady-state (i.e. the base year SAM dataset). This implies that changes in the real wage are driven by changes in the unemployment rate, which also determines the changes in employment ${ }^{14}$.

All simulations are run in a multi-period setting. The periods can be interpreted as years as annual data has been used both for the benchmark SAM dataset and for behavioural relationships. The model is assumed to begin in long-

\footnotetext{
${ }^{13}$ Other labour market configurations are possible in the AMOS framework, but we do not investigate these in this paper.

${ }^{14}$ Empirical support for the wage curve specification can be found in Blachflower and Oswald (2005), Devicienti et al. (2008), and Montuenga et al. (2003).
} 
run equilibrium. This implies that with no exogenous shocks, the model will replicate the initial values over all subsequent time periods.

Within each period of the simulations, both the total capital stock and the labour force (and their sectoral compositions) are fixed, and commodity markets clear continuously. However, a key feature of the AMOS model is the betweenperiod updating of capital stocks and the labour force. For the capital stock, gross investment is given by an explicit capital-stock adjustment mechanism. In each period investment demand from each sector is equal to depreciation plus a proportion of the difference between actual and desired capital stock, where desired capital stock is a function of commodity output, the nominal wage and the user cost of capital. Hence sectoral investment in each period is the sum of a portion $(\lambda)$ of the gap between desired capital stock $\left(K^{*}\right)$ and actual capital stock $(K)$ in the current period, and the depreciation rate $(\delta)$ :

$$
\Delta K_{i, t}=\lambda\left(K_{i, t}^{*}-K_{i, t}\right)+\delta_{i} K_{i, t-1}
$$

Equation 4

This specification of the adjustment of capital stock is consistent with Jorgenson (1963) as well as that proposed by Uzawa (1969), in which capital stock gradually adjusts to its desired level. 
For the labour force, it is assumed that there is no natural population increase and that international migration can be ignored. The labour force adjusts between periods through inter-regional migration flows. The migration specification is based on the Harris and Todaro (1970) model. Net migration to Scotland is positively (negatively) related to the real wage (unemployment rate) differential between Scotland and the rest of the UK. The regional economy is assumed to have zero net migration in the base year (2006) and net migration flows act to re-establish this equilibrium over time. The specific form of the migration equation is the same as used by Layard et al. (1991):

$$
\ln \left[\frac{m^{S}}{L^{S}}\right]=\mu-0.08\left[\ln u^{S}-\ln u^{R}\right]+0.06\left[\ln \left[\frac{w^{S}}{c p i^{S}}\right]-\ln \left[\frac{w^{R}}{c p i^{R}}\right]\right] \quad \text { Equation } 5
$$

where $\mu$ is a parameter calibrated to ensure zero net migration in the base year, $m$ is migration, $L$ is the labour force, $u$ is the unemployment rate, $w$ is the wage rate, cpi is the consumer price index and superscripts $S$ and $R$ respectively refer to Scotland and the (non-modelled) rest of the UK. Long-run equilibrium in the labour market is reached when the ratios between unemployment and real wage rates in Scotland and the rest of the UK are at their previous levels (Gilmartin et al., 2013). It is assumed that there is no natural population change, or international migration. 


\subsection{Simulation strategy}

We run the AMOS model in a period-by-period setting. The expenditures related to marine energy development in Scotland - as given by S\&I (2009) - are introduced as exogenous disturbances to output demand for specific sectors. We simulate the exogenous expenditure shocks for each of the three installation scenarios ('base case, 'down side and 'stretch') for the annual expenditures on marine energy developments published by S\&I (2009). We use the development paths for marine capacity (in MW) and the assumed cost of each unit of capacity in the three scenarios to calculate the expenditure disturbances that are then introduced in the AMOS model.

Calculating the expenditure shocks requires four steps: first, the total expenditures for eleven years (i.e. from 2010 to 2020, inclusive) are deflated from 2009 prices to 2006 prices, to be consistent with the AMOS model dataset. Second, the total expenditures in each year are shared across the categories of costs, as detailed in S\&I (2009) ${ }^{15}$. Third, we use the share of spending in each category which is likely to be sourced in Scotland - as given in S\&I (2009) - to give the Scottish expenditures by category. Fourth, we allocate the expenditure categories to corresponding sectors in the AMOS model and calculate the expenditure injection into each of these sectors. Using this procedure, the Scottish component of

\footnotetext{
15 These categories are given in Table 2, along with the share of annual total expenditures in each category, the shares of expenditure in each category assumed to be sourced in Scotland (and outside Scotland), and the sector of the model to which each category of spending is allocated.
} 
expenditures from twenty-three categories are each allocated to one of eight sectors of the twenty five sector AMOS model (these are one of the first eight sectors in Appendix A).

The expenditure in each sector in each year is calculated from the total (worldwide) expenditure on each cost category $\mathrm{j}$ in each year $t$, and uses a categoryspecific factor $\left(\beta_{j}\right)$ which estimates the share of spending in that cost category that is sourced in Scotland. Ex is the level of expenditure, and super-scripts $S$ and W relate to Scotland and World, respectively. It is assumed that $\beta_{j}$ is constant for all values of $t$. This formula is used for each $n$ category which is allocated to sector $i$ of the model. The parameter $\eta_{t}$ is the deflator to translate costs in year $t$ to 2006 prices.

$$
E x_{i, t}^{s}=\left(\sum_{j=1}^{n} \beta_{j} E x_{j, t}^{W}\right) \eta_{t}
$$

Several points should be noted about this calculation. Firstly, the costs of each MW of capacity are taken from the S\&I (2009) publication, (where the per MW cost of installed capacity in each scenario falls over time (Figure 1)).

[Figure 1] 
Secondly, we assume that the distribution of costs across categories (Table 2) remains constant across all three scenarios for each period. For example, the cost of the device structure is $34 \%$ of the annual expenditure in each scenario for each year between 2010 and 2020. This, combined with a declining total cost for each MW implies cost reductions are equal across the categories of expenditures. We adopt this as a working assumption for this analysis, though we acknowledge that in practice cost reductions may occur at different rates for different categories of expenditure. Thirdly, we assume that the regional sourcing for each cost category remains constant across the years of the simulations. This would ignore the possibility that increased development of marine energy capacity in Scotland could lead to a local supply chain in which a greater share of spending in each category might be sourced within Scotland. In later sensitivity analysis, we investigate the impact of increasing the Scottish retained share of expenditures in each category ${ }^{16}$. Following this methodology, the annual expenditures in Scotland for the three alternative installation scenarios for marine renewables are simulated in our CGE framework as a series of sector-specific exogenous demand shocks. There are eight shocks in each period and eleven periods of expenditure shocks (from 2010 to

\footnotetext{
${ }^{16}$ From Table 2 we note that almost half $(48.8 \%)$ of the total annual expenditure is in the 'Structure' (34.4\%) and 'Mechanical plant' (14.4\%) cost categories. 'Moorings and foundations' are estimated to compromise a further $10 \%$ of total annual costs. The extent to which these three categories are assumed to source their inputs from within Scotland varies significantly. Of these three categories, only 'Structure' has more than two-thirds of expenditures sourced in Scotland. Multiplying the share of annual expenditures in each category and the categories' Scottish share to construct a weighted average, we calculate that $52.7 \%$ of all expenditures will be sourced in Scotland - this is the source for the estimate of $\alpha$ used in Equations 1 and 2.
} 
2020 inclusive) making 88 shocks in total. The counterfactual in each case is that there is no change in the Scottish economy, i.e. the base year (2006) would recreate itself as it is in a long-run equilibrium. All results, therefore, can be attributed solely to the sectoral expenditure shocks. The AMOS model is run in its period-by-period setting for one hundred periods (years) with the transitory expenditures introduced for the first eleven periods. The model is run forward for a further eighty-nine periods with no further shocks to demand.

In performing the simulations described above, we focus only on the absolute change in Scottish marine energy installations. The degree of adoption of marine energy (and renewable energy generally) in the rest of the UK (and indeed the rest of the world) will likely have consequences on the ultimate impact of the installation expenditures in Scotland. This is because a simultaneous change in RUK demand (as a consequence of renewables expenditures) will have feedback effects in Scotland through, for example, interregional trade linkages or interregional migration. Thus we do note that the overall impact of the energy policy change in Scotland may be affected by the relative intensity of the policy vis a vis the RUK (or ROW). We focus here only on the absolute change in Scottish renewable energy installations since (i) the majority of the UK's marine (and indeed renewable) resources are located in Scotland, so the impacts are likely to be concentrated in Scotland, and (ii) the size of 
the impacts, as a percentage of GDP, are likely to be relatively small, limiting the potential for other-region or other-country 'spillover' effects ${ }^{17}$.

\section{Results}

\subsection{Aggregate results: 'base case' scenario}

We are particularly interested in the effects of expenditures on regional employment over the simulation period. Figure 2 shows: the employment effects as reported in S\&I (2009); the employment effects we estimate using employmentoutput coefficients ('Direct $\mathrm{IO}^{\prime}$ ) and the Type 1 and Type 2 employment-output multipliers, calculated from the IO data (2006) for Scotland for the same sectoral aggregation as the CGE model; and the results from the CGE analysis with the model setup as described in Section 3.2. This gives five series for employment in Scotland over the simulation period for the 'base case' scenario. The S\&I (2009) results only relate to the years 2010 to 2020 - as do the IO figures - as these are the years in which expenditures are made. In Figure 2, the series labels are ordered (from highest to lowest) by the employment impact in year 2020.

\footnotetext{
${ }^{17}$ The interregional and spillover consequences of a policy-induced demand disturbance in Scotland is considered in Gilmartin et al. (2013), where the authors use a (less disaggregated) variant of AMOS. The authors find that non-target region GDP effects are non-zero and, in some cases, larger than in the target region, Scotland (depending on the specification of interregional labour market linkages). The size of the demand disturbance as a percentage of GDP is far larger than in this research, however, so any spillover effects are likely to be small in our case. We do note, however, the usefulness of research into the potential for other-region spillover effects to mitigate or otherwise the impact of regional policy.
} 
[Figure 2]

For the CGE results, we observe two distinct phases: the 'concurrent' phase, during which expenditures occur (i.e. 2010 to 2020 inclusive) and the 'legacy' phase, from 2021 onwards. Only in the CGE case are there employment effects during and after the period of expenditures. During the concurrent phase, increased expenditure acts as a pure demand stimulus: the prices of Scottish goods and services are bid up, raising profitability in the directly stimulated sectors (and those indirectly linked to the stimulated sectors) and encouraging sectoral expansion and higher employment. We will examine the sectoral distribution of employment gains (and losses) later in this section.

Comparing the results from the CGE method and those published by S\&I (2009) during the 'concurrent' phase, we see that the absolute change in employment in Scotland is broadly similar. By the end of this phase (2020) S\&I (2009) predict employment in Scotland will be 2,647 higher. Our CGE results estimate that employment in the same year is 2,981 above its base level. While these figures are broadly similar in terms of their order of magnitude, it is interesting to compare the results over the 'concurrent' phase from the CGE and IO results. Recall that S\&I (2009) argue that their results relate only to employment directly created by the 
expenditures, and that the additional indirect and induced effects of job changes should also to be taken into account over and above the direct effects. The implication of this is that the S\&I (2009) results likely underestimate the 'true' effect on employment.

Comparing the CGE and IO results, we find that the CGE employment results are (slightly) below the estimate of the 'direct' jobs created in the sectors experiencing the demand boost calculated using IO data. In aggregate therefore, the CGE results suggest that an IO estimate of the direct jobs created by these expenditures would overestimate the number of jobs created, although the difference in employment in 2020 is small (3,025 in the 'Direct IO' case against 2,981 from the CGE results). The Type 1 and Type 2 IO employment results considerably overstate the impact of these expenditures on employment in Scotland over the period of expenditures. This is an unsurprising result, given the absence of supply side constraints associated with IO calculations.

[Figure 3 here]

The sectoral distribution of absolute employment changes in 2020, calculated using IO and CGE methods, are shown in Figure 3. Employment impacts by sector were not published by S\&I (2009). Figure 3 shows that in some sectors in the CGE 
model there are small declines in employment by 2020, with employment in the 'Gases, chemicals and pharmaceuticals', 'Other private business services' and 'Other manufacturing' sector down by 187, 126 and 118 respectively from their base levels. Employment is higher in all eight of the sectors which experience the exogenous expenditure shock. Employment also increases in 'Wholesale, retail, hotels and restaurants' by 143, as well as being higher than base year in 'Other services' (20) and 'Water' (2).

For the 'legacy' phase (Allan et al., 2008) of the results, we examine the impact on employment in Scotland after the expenditures cease in 2020. In the IO cases, there are no further impacts on employment as this is a demand-driven system - and there are no further demand shocks. Using a CGE model, however, in which regional demand and supply interact, we observed (Figure 2) a continuing effect on regional employment. The results below demonstrate both the value of CGE modelling of the impact of demand-side disturbances over models in which the supply-side is assumed passive (such as IO), and what features of the CGE model employed here produce impacts which last beyond the expenditures themselves. From these simulations we can argue that the impact of transitory demand-shocks on regional employment are overestimated by $\mathrm{IO}$ analysis during the period of expenditures, and underestimated when the expenditures cease.

The active supply-side in AMOS involves the treatment of migration and investment flows between the region and the exogenous (unmodelled) economy 
outside the region. As previously stated, migration is assumed to respond to regional real wage and unemployment differentials between Scotland and the rest of the UK. Real wages in Scotland are bid up from their initial levels as demand (and sectoral output) rises. This expands the labour force in Scotland via a (slight) increase in the participation rate, and positive net migration from the rest of the UK.

Migration is crucial for the response of the Scottish economy in the 'legacy' phase. Legacy effects are observed as the expenditures lead to an increase in factor supplies (of labour and capital) which remain after the expenditures cease. Demigration and disinvestment occur slowly, so that the initial demand-side shock produces a positive supply-side shock which allows output to increase. The dynamics of the real and nominal wages show this point clearly (Figure 4). The pattern is the same in the other two scenarios.

[Figure 4 here]

Both the real and nominal wages increase in the concurrent phase. Expenditures place upward pressure on wages and prices so that some exports are crowded out by the increase in domestic activity. This explains, partly, the reduction in employment in some sectors (Figure 3), as their activity is crowded out by increased expenditures in other sectors. From 2021, the real and nominal wages 
decline sharply so that both are lower than their initial values. These lower wages following the end of the expenditures - with real wages down $0.048 \%$ in 2021 - act as a stimulus to the Scottish economy.

Figures 5 and 6 illustrate the evolution of capital rental rates (the return on capital) in the 'stimulated' sectors (which directly experience an increase in demand) and the 'non-stimulated' sectors, respectively.

[Figure 5 here]

[Figure 6 here]

The return on capital in the 'stimulated' sectors increases significantly during the concurrent phase - rising by more than $20 \%$ in the 'Electric motors and generators' sector in the final period of expenditures (2020). The increase in profitability in these sectors initially means that desired capital stock exceeds actual capital stock, so investment occurs. After the expenditures end, the return on capital in the stimulated sectors falls - these sectors have too large a capital stock for the new (post-expenditure) level of demand. Capital stock is reduced over time through depreciation. The return on capital peaks for the (majority of) non-stimulated sectors 
in the period immediately after the end of the expenditures (i.e. 2021). Over time, the return on capital returns to its initial level in all sectors.

Figures 7 and 8 illustrate the evolution of output changes in the 'stimulated' and 'non-stimulated' sectors separately. Prices rise in these sectors during the concurrent phase, increasing output, the return on capital, subsequent investment and therefore capital stock (Allan et al., 2008). The non-stimulated sectors will be affected indirectly through links to the stimulated sectors, and so might experience expansions in output, or crowding out effects, especially driven by increases in the wage rates and competition between sectors in a tightening labour market.

[Figure 7 here]

[Figure 8 here]

Comparing Figures 7 and 8, we observe that the 'stimulated' sectors experience the largest percentage deviations from their initial levels. In the 'Electric motors and generators' sector, for instance, output increases by over $12 \%$ in 2020 , while there are increases of more than $5 \%$ in this year in the 'Insulated wire and cable', 'Electrical equipment' and 'Articles of concrete' sectors. For sectors that are 
not directly affected by the expenditures, the output effects are more modest -Figure 8 shows that by 2020 the impact on the output of the majority of the non-stimulated sectors is negative - although there are increases in output in four sectors. Again there is a spike in output in 2020 with a discontinuous adjustment for all sectors as the expenditures end. A few years into the legacy phase - from 2024 onwards - the output of all sectors (stimulated and non-stimulated) is higher than initially, and this continues until the end of our simulation period. In the long-run, sectoral output converges back to its initial levels, given that the demand shock is transitory.

\subsection{Discounting, sectorally disaggregated expenditure-employment effects and impacts of increased local (i.e. Scottish) sourcing}

As established in Section 4.1, a CGE analysis of expenditures reveals that there are significant 'legacy' effects on the Scottish economy, including employment benefits, which occur during the (20 year) simulation period. In this section, we analyse these employment effects in more detail. First, we calculate the present value of the employment legacy effects. Second, we decompose the CGE simulation results to consider how the different sectoral expenditures impact on aggregate employment. Since policy makers are keen to support the establishment of a domestic supply chain to the marine energy industry, information on which sectors are associated with relatively high employment-creation would provide an important addition to the knowledge base of policy makers. 
We discount the estimated Scottish employment effects and Scottish expenditures to calculate the impact on employment (in present values) of each $£$ spent on the Scottish economy. In calculating the present value of employment associated with the expenditure stimulus, we are applying the principle that a job today is worth more than a job tomorrow, due to individuals (and society) having a positive rate of time preference ${ }^{18}$. We use a discount rate of $2.5 \%$ for both expenditures and employment, in line with HM Treasury (2003).

We calculate that each $£ 1$ million expenditures (in present values) creates 24.24 net employments (in present values) in the base case scenario. In comparison, the net employment creation for each $£ 1$ million expenditures in the 'downside' and 'stretch' scenarios are 24.33 and 23.64 respectively. These figures suggest that expenditures of $£ 4$ million (in present values) will bring about a net increase in employment in Scotland of around 100 (in present values). This figure is directly linked to the retained expenditures and takes account of the employment effects beyond the end of the expenditures.

We also consider the impact of each of the different sectoral expenditures on Scottish employment, since we anticipate that some sectoral expenditures will have higher employment-creation effects due to different intermediate input and labour requirements. Other things being equal, a boost to a sector with high employment

\footnotetext{
${ }^{18}$ The time-discounting of non-monetary variables is used in areas as diverse as health (De Kok et al., 2010), diet (Ikeda et al., 2010) and the environment (e.g. Philbert, 1999). The UK Treasury offers advice on the discounting of impacts in its Green Book (HM Treasury, 2003).
} 
(and therefore a high employment-output multiplier) should produce a greater change in regional employment than the same shock applied to a sector with low employment (and a low employment-output multiplier). By modelling the eight sectoral expenditure shocks from the 'base case' scenario separately, we can estimate the employment effects of each sectoral expenditure stream. As with the aggregate results reported above, we calculate the present value of the expenditures and employment effects. The results are shown in Figure 9.

[Figure 9 here]

The strongest employment-creation impact of the expenditures occur in the 'Insulated wire and cables' sector (Figure 9), where, expressed in present value terms, each $£ 1 \mathrm{~m}$ of expenditures increases employment in the sector by 72.18 . The lowest value is for the 'Construction' sector (6.73 jobs). This is an important result as it shows that it is not only important to retain volumes of expenditures, but that the impact on overall regional employment can be significantly affected (by up to a factor of ten), depending on which sectors are directly affected by the expenditure stimulus.

Additionally, we calculate the impact of increasing the share of expenditures retained in Scotland, and we do this for each separate expenditure category. In line 
with S\&I (2009), we assume that 52.7\% of the (worldwide) expenditures necessary to establish marine energy capacity in Scotland would be retained in Scotland. This is an average of the assumed degree of local sourcing across each expenditure category (see footnote 16). Individually, some expenditure categories have a higher local sourcing rate (e.g. onshore civil engineering at 90\%) and others lower (e.g. component testing at $40 \%$ ) (Table 2). Here, we calculate the employment impacts of increasing the degree of local sourcing for each expenditure category.

We recalculate the expenditures input to the model with a 1 percentage point higher share of retained expenditure for each cost category in Scotland. For instance, for the 'Structure' category, we previously followed S\&I (2009) and assumed that $70 \%$ of the costs under this category were made in Scotland; in our new simulation we assume that $71 \%$ of the expenditures in this category are made in Scotland. For all other categories of expenditure, the share of retained expenditures remains unchanged at the original share. We do this simulation twenty-three times - once for each of the expenditure categories, and we compare the results of each of these scenarios with our base case simulation. This reveals the employment-creation impacts of an increase in local sourcing for each expenditure category over the simulation period. Our results are shown in Figure 10.

[Figure 10 here] 
Figure 10 illustrates that the impact on employment of increasing local sourcing by $1 \%$ differs considerably across the categories. Increasing local sourcing by $1 \%$ in three categories - 'Control and monitoring systems, 'Onshore equipment' and 'Logistics base (e.g. ports and harbours)' - increases employment over the period by approximately zero. At the other extreme, the largest effect on employment occurs in the 'Structure' category - where employment is increased by 249. Part of this difference can be explained by a categories share of total costs ${ }^{19}$. More interestingly however, is the fact that from our simulations there is a large impact on employment (95) - the second largest across all categories, behind only 'Structure' - from a one percentage point increase in local sourcing of 'Cables, umbilicals and communications', despite this category comprising only $5.3 \%$ of total costs in each year. Several other categories have higher shares of total costs, but a lower impact on employment across the simulation period from increased local sourcing. This result can be understood by considering the sector into which the expenditures on 'Cables, umbilicals and communications' are allocated (sector 4: 'Insulated wire and cable'). As Figure 9 shows, each unit of expenditure in this sector has the largest impact on employment over the simulation period. In the next section, we consider the policy implications of our simulation results, including this sectoral analysis.

\footnotetext{
19 The three categories listed above, for example, are $0.93 \%, 1.07 \%$ and $1.13 \%$ of total annual expenditures, respectively, while the 'Structure' category accounts for $34 \%$ of total annual expenditures.
} 


\section{Retained expenditures: available capacity, sectoral knowledge and skills}

The retention (in Scotland) of expenditures related to marine energy developments in Scotland will depend upon a number of factors. These will include the existence of knowledge and experience in the appropriate technologies and techniques, the extent of government support, and the distance to the development from existing sources of products and the relevant transportation costs. Further, existing capacity would be expected to act as a draw for further development of a Scottish supply-chain to expand domestic production. Some aspects of early marine energy developments in the UK have been outsourced: for example, with the SeaGen tidal energy turbine installed in Northern Ireland in April 2008, British engineering firms were contracted to build, test and monitor the turbine, whilst the components were manufactured in various locations in the UK and Europe, and a Belgian firm was contracted for the deployment stage.

Experiences from other renewable energy projects also suggest that major components may be imported: Lewis and Wiser (2007) note that out of the 889MW worth of onshore wind power installed in the UK in 2004, $0 \%$ of the turbine component parts were manufactured in the UK. Recent anecdotal evidence for the UK suggests that the wind energy industry remains import-dependent, and is focused on turbine assembly, rather than the production of devices. Thus, there is an argument that the UK missed an opportunity to develop an embedded wind energy 
industry due to a lack of focused policy support to help establish a domestic supply chain for the industry ${ }^{20}$.

The development of the marine energy sector could potentially be quite different if there are appropriately-designed policies to support the industry. The prospects for the sector do appear encouraging. Already, there is a significant marine energy production capacity across the UK, and there are indications that a supply chain is already developing, at least in Scotland (Scottish Renewables Forum, 2007). However, since many marine energy technologies are in the early stage of development and parts tend to be specialised and not mass produced, there could be constraints in terms of lead times, costs, and the supply of skilled labour (NOF energy, 2008). As such, it is likely that some of the contracts associated with anticipated Scottish marine energy installations will be awarded outside the region. Identifying the potential value of an appropriate supply chain is particularly important for the design of sensible policy, since some aspects of the supply chain will have more economic value than others. Where the focus of regional policy makers is on job creation, it is important to determine those sectors in the supply chain which may have the most beneficial expenditure-employment links.

The results in Figures 9 and 10 help to illustrate this point. Figure 9 shows that transitory expenditures in different sectors have important consequences for

\footnotetext{
${ }^{20}$ Lewis and Wiser (2007) conduct a cross-country comparison of the policy support mechanisms that have been employed to support wind power industry development. They argue that other countries' policy measures have been more successful at developing large indigenous wind turbine manufacturers compared to the UK.
} 
aggregate employment. Total impacts on employment of each unit of expenditure can vary by a factor of as much as ten. Figure 10 demonstrates that the specific category of costs in which local sourcing is increased can be critical for the impact on aggregate employment. This need not necessarily be in the category in which the largest share of the costs is concentrated (although, in this instance, this is where the largest impact on employment occurs).

\section{Conclusions}

In this paper we model the link between (transitory) expenditures related to marine energy manufacturing and installations and regional employment change using a CGE framework parameterised on the Scottish economy. A CGE model is a particularly suitable framework for the analysis since it can consider the multisectoral impacts on the region and, since it incorporates a full specification of demand and supply side activity, can deal appropriately with crowding-out over competition for regional resources.

Our approach represents a more comprehensive and transparent attempt to estimate the economic impacts of investments in renewable energy capacity than that available in the literature. The analysis is specific to the case of marine energy expenditures in Scotland, but the methodology is replicable and the underlying principles are relevant across regions and technologies. As regional governments 
look to justify policy support for renewable energy based at least partly on anticipated economic benefits, our findings make a valuable contribution to policy makers' knowledge base.

Our results suggest that using an IO model, rather than a CGE model, could potentially overstate the employment effects for Scotland of marine energy expenditures in the short run, and understate the effects in the long run. During the period of expenditures, the estimate of the direct employment effect is comparable to that of the aggregate CGE results for employment. Taking account of the sectoral crowding-out caused by competition for scarce factors of production (and the resulting price increases and reduced competitiveness), in some sectors output and employment fall, while in others economic activity rises. Beyond the period of expenditures themselves, the CGE analysis reveals the extent of 'legacy' effects of temporary demand-side disturbances. These are not captured by conventional demand-side IO analysis for temporary expenditure impacts. They are caused by the responses of an active supply-side - for instance through increased immigration and capital stock adjustments - which is absent in an IO framework.

Additionally, we examine the link between sectoral expenditures and regional employment. A detailed examination of the aggregate employment effects, and the marginal impact of increasing domestic sourcing for each sector, is vital for sound policy-making. In our analysis we identify those expenditures which could provide the most benefit to the regional economy. 
Further research should examine the assumed nature of migration to the region. In this paper, we assume myopic behaviour on the part of migrants. This assumption has important consequences for determining the adjustment path of the economy in response to a transitory demand disturbance (including supply-side adjustments). Adopting a forward-looking perspective could generate a different adjustment path, and a different set of results. Furthermore, some evidence suggests that adopting renewable technologies could have a non-neutral (positive) impact on the costs of providing electricity to industries and households. This increase in the cost of supply could offset some of the economic benefits of marine energy expenditures observed in this paper. Cost benefit analyses, which incorporate a wider assessment of the costs and benefits associated with renewable energy provision, would provide an indication of the net welfare benefits of renewable energy supply and would complement economic analyses of the type provided in this paper. 
Acknowledgements: The authors would like to thank two anonymous referees and the Editor for their valuable feedback and contributions to this research. One author acknowledges funding from ClimateXChange, the Scottish Government funded Centre of Expertise in Climate Change. The views expressed remain the sole responsibility of the authors.

References

AEA Technology and Poyry Energy Consulting. (2006). Additional support for marine electricity generation in Scotland. Volume 1 - Summary Report.

AEA Technology and Poyry Energy Consulting. (2007). Additional support for marine electricity generation in Scotland. Volume 2 - Main Report. 
Allan, G.J., Bryden, I., McGregor, P.G., Stallard, T., Swales, J.K., Turner, K., \& Wallace, A.R. (2008). Concurrent and legacy impacts from establishing a marine energy sector in Scotland. Energy Policy, 36(7), 2734-2753.

Armington, P. (1969). A theory of demand for products distinguished by place of production. IMF Staff Papers, 16, 157-178.

Arthur D Little. (2005). Wave Hub - Summary business case (Report to the South West of England Regional Development Agency).

Blanchflower, D.G. \& Oswald, A.J. (2005), "The wage curve reloaded", NBER Working paper, No. 11338.

Carbon Trust. (2011). Marine Renewables Green Growth Paper.

De Kok, I.M.C.M., Habbema, J.D.F., van Rosmalen, J. \& van Ballegooijen, M. (2010). Would the effect of HPV vaccination on non-cervical HPV-positive cancers make the difference for its cost-effectiveness? European Journal of Cancer, 47(3), 428-435.

Department for Business Enterprise and Regulator Reform. (2008). Atlas of UK marine renewable energy resources: Atlas pages, a strategic environmental assessment report. March.

Department for Energy and Climate Change. (2011). The UK Renewable Energy Strategy. 
Devicienti, F., Maida, A. \& Pacelli, L. (2008), “The resurrection of the Italian wage curve", Economic Letters, Vol. 98 (3), p. 335-341.

European Parliament. (2009). Directive 2009/28/EC of the European Parliament and of the council of $23^{\text {rd }}$ April 2009 on the promotion of the use of energy from renewable sources and amending and subsequently repealing Directives 2001/77/EC and 2003/30/EC. Official Journal of the European Union, L140/16, June.

Forum for Renewable Energy Development in Scotland. (2004). Marine Energy Group report: Harnessing Scotland's marine energy potential. Scottish Executive, Edinburgh.

Ghosh, A. (1958). Input-output approach in an allocation system. Economica, 25 (97), $58-64$.

Gilmartin. M., Learmonth, D., McGregor, P., Swales, J.K., \& Turner, K. (2013). Regional policy spillovers: The national impact of demand-side policy in an interregional model of the UK economy. Environment and Planning $A$, forthcoming.

Hanley, N., McGregor, P.G., Swales, J.K. \& Turner, K. (2009). Do increases in energy efficiency improve environmental quality and sustainability? Ecological Economics, 68(3), 692-709. 
Harrigan, F., McGregor, P.G., Dourmashkin, N., Perman, R., Swales, J.K. \& Yin, Y.P. (1991). AMOS: A micro-macro model of Scotland. Economic Modelling, 8, 424479.

Harris, J.M. and Todaro, M. (1970). Migration, unemployment and development: a two-sector analysis. American Economic Review, 60, 126-142.

HM Treasury. (2003). Green Book: Appraisal and evaluation in central government: Treasury guidance. London, The Stationary Office.

Ikeda, S., Kang, M.-I. \& Ohtake, F. (2010). Hyperbolic discounting, the sign effect and the body mass index. Journal of Health Economics, 29, 268-284.

Jorgenson (1963). Capital theory and investment behaviour. American Economic Review, 53(2), 247-259.

Krohn, S. (1998). The wind turbine market in Denmark. Danish Wind Industry Association.

Krugman, P. R. (1980). Scale economies, product differentiation, and the pattern of trade. American Economic Review, 70(5), 950-959.

Layard, R., Nickel, S. \& Jackman, R. (1991). Unemployment - macroeconomic performance and the labour market. Oxford University Press, Oxford. 
Lewis, J., \& Wiser, R. (2007). Fostering a renewable energy technology industry: An international comparison of wind industry policy support mechanisms. Energy Policy, 35, 1844-1857.

Loveridge, S. (2004). A typology and assessment of multi-sector regional economic impact models. Regional Studies, 38(3), 305-317.

Marine Institute and Sustainable Energy Ireland. (2005). Analysis of the potential economic benefits of developing ocean energy in Ireland.

McGregor, P.G., Swales, J.K. \& Yin, Y.P. (1996). A long-run interpretation of regional input-output analysis. Journal of Regional Science, 36, 479-501.

Miller, R.E. \& Blair, P.D. (2009). Input-output analysis: Foundations and extensions (2nd Edition). Cambridge University Press, Cambridge.

Montuenga, V., Garcia, I., Fernandez, M. (2003), “Wage flexibility: Evidence from five EU countries based on the wage curve", Economic Letters, Vol. 78, No. 2, p. 169-174.

NOF Energy. (2008). Business support for the UK oil, gas and energy sectors. Article provided by Douglas Westwood Consulting, available online at http://www.nofenergy.co.uk/read.php?read=20\&parent=4\&sub=20\&category= 
Pappas, N. (2008). Can migrants save Greece from ageing? A computable general equilibrium approach using G-AMOS. University of Strathclyde Discussion Papers in Economics 08-01

Philibert, C. (1999). The economics of climate change and the theory of discounting. Energy Policy, 27, 913-927.

Scottish Government. (2007). The government economic strategy. Scottish Government, Edinburgh.

Scottish Government. (2009). Renewables action plan. Scottish Government, Edinburgh.

Scottish Government. (2011). 2020 routemap for renewable energy in Scotland. Scottish Government, Edinburgh.

Scottish Renewables Forum. (2007). Scottish renewables economics impact report. Available online at http://www.scottishrenewables.com/MULTIMEDIA GALLERY/1DF99F66-E5BD-4823-82C3-10F3F501D30D.PDF

Sgurr Energy and IPA. (2009). Marine energy supply chain survey (Report prepared for Scottish Government Marine Energy Group). July 2009.

Sovacool, B. K., Lindboe, H. H., \& Odgaard, O. (2009). Is the Danish wind energy model replicable for other countries? The Electricity Journal, 22(3), 4. 
Stern, N. (2006). Stern review on the economics of climate change. HM Treasury, The Stationary Office, London.

Stern, N. (2008). Speech by Lord Stern of Brentford at the Climate Ratings Agency, London, 25 $5^{\text {th }}$ June 2008

Turner, K., Munday, M., McGregor, P. \& Swales, J.K. (2012). How responsible is a region for its carbon emissions? An empirical general equilibrium analysis. Ecological Economics, 76(c), 70-78.

Uzawa, H. (1969). Time preference and the Penrose Effect in a two-class model of economic growth. Journal of Political Economy, 77(4), Part 2: Symposium on the Theory of Economic Growth, 628-652.

Walras, L. (1926). Elements of pure economics or the theory of social wealth. Edition definitive, translated by: Jaffe, W. (1954), London: George Allen and Unwin Ltd. 
Table 1a: Annual and cumulative Scottish capacity (MW) andglobal expenditures for three marine energy deployment scenarios in Scotland (2009 prices).

\begin{tabular}{|c|c|c|c|c|c|c|c|c|c|c|c|c|}
\hline & \multicolumn{4}{|c|}{ 'Downside' } & \multicolumn{4}{|c|}{ 'Base case' } & \multicolumn{4}{|c|}{ 'Stretch' } \\
\hline 2011 & 10 & 17 & 45 & 71 & 10 & 17 & 45 & 71 & 20 & 33 & 87 & 140 \\
\hline 2012 & 10 & 27 & 40 & 111 & 20 & 37 & 76 & 147 & 40 & 73 & 151 & 291 \\
\hline 2013 & 0 & 27 & 0 & 111 & 40 & 77 & 132 & 279 & 80 & 153 & 262 & 553 \\
\hline 2017 & 65 & 142 & 191 & 468 & 115 & 399 & 277 & 1,125 & 228 & 796 & 544 & 2,220 \\
\hline 2018 & 85 & 227 & 228 & 696 & 148 & 547 & 336 & 1,461 & 297 & 1,093 & 665 & 2,885 \\
\hline 2019 & 110 & 336 & 274 & 970 & 193 & 740 & 414 & 1,875 & 386 & 1,480 & 816 & 3,701 \\
\hline 2020 & 143 & 479 & 332 & 1,302 & 251 & 991 & 508 & 2,383 & 502 & 1,982 & 1,002 & 4,703 \\
\hline
\end{tabular}

Source: SEI (2009). 
Table 1b: Retained expenditures and employment impacts on Scotland under three scenarios of marine energy development in Scotland

\begin{tabular}{|c|c|c|c|c|c|c|}
\hline & \multicolumn{2}{|c|}{ 'Downside' } & \multicolumn{2}{|c|}{ 'Base case' } & \multicolumn{2}{|c|}{ 'Stretch' } \\
\hline & $\begin{array}{l}\text { Cumulative } \\
\text { spending in } \\
\text { Scotland } \\
\text { (Emillion) }\end{array}$ & $\begin{array}{c}\text { Employment in } \\
\text { Scotland }\end{array}$ & $\begin{array}{l}\text { Cumulative } \\
\text { spending in } \\
\text { Scotland } \\
\text { (Emillion) }\end{array}$ & $\begin{array}{c}\text { Employment in } \\
\text { Scotland }\end{array}$ & $\begin{array}{l}\text { Cumulative } \\
\text { spending in } \\
\text { Scotland } \\
\text { (Emillion) }\end{array}$ & $\begin{array}{c}\text { Employment in } \\
\text { Scotland }\end{array}$ \\
\hline 2010 & 14 & 53 & 14 & 53 & 28 & 105 \\
\hline 2011 & 37 & 105 & 37 & 105 & 74 & 211 \\
\hline 2012 & 59 & 105 & 77 & 211 & 154 & 422 \\
\hline 2013 & 59 & 0 & 147 & 422 & 292 & 844 \\
\hline 2014 & 59 & 0 & 230 & 548 & 454 & 1,097 \\
\hline 2015 & 59 & 0 & 329 & 717 & 648 & 1,426 \\
\hline 2016 & 146 & 527 & 447 & 917 & 884 & 1,853 \\
\hline 2017 & 247 & 685 & 593 & 1,213 & 1,170 & 2,409 \\
\hline 2018 & 367 & 891 & 770 & 1,561 & 1,521 & 3,132 \\
\hline 2019 & 511 & 1,158 & 989 & 2,035 & 1,951 & 4,072 \\
\hline 2020 & 687 & 1,506 & 1,257 & 2,647 & 2,480 & 5,293 \\
\hline
\end{tabular}

Source: SEI (2009). 
Table 2: Categories of expenditure, share of annual expenditure which falls in each category, share of expenditure by location and sector to which category is assigned

\begin{tabular}{|c|c|c|c|c|}
\hline \multirow[b]{2}{*}{ Category } & \multirow[b]{2}{*}{$\begin{array}{l}\text { Share of annual } \\
\text { expenditure in } \\
\text { this category }\end{array}$} & \multicolumn{2}{|c|}{ Location of expenditure } & \multirow[b]{2}{*}{$\begin{array}{c}\text { Sector in } \\
\text { AMOS } \\
\text { model }\end{array}$} \\
\hline & & Scotland & $\begin{array}{l}\text { Outside } \\
\text { Scotland }\end{array}$ & \\
\hline Conceptual engineering & $0.33 \%$ & $50.0 \%$ & $50.0 \%$ & 8 \\
\hline Expert resource & $0.28 \%$ & $45.0 \%$ & $55.0 \%$ & 8 \\
\hline Site/resource assessment & $0.80 \%$ & $58.3 \%$ & $41.7 \%$ & 8 \\
\hline Detailed engineering & $0.77 \%$ & $43.8 \%$ & $56.2 \%$ & 8 \\
\hline Component testing & $0.73 \%$ & $40.0 \%$ & $60.0 \%$ & 8 \\
\hline Systems integration testing & $0.70 \%$ & $56.7 \%$ & $43.3 \%$ & 8 \\
\hline $\begin{array}{l}\text { Verification third party } \\
\text { approvals }\end{array}$ & $0.45 \%$ & $25.0 \%$ & $75.0 \%$ & 8 \\
\hline Structure & $34.37 \%$ & $69.6 \%$ & $30.4 \%$ & 3 \\
\hline Mechanical plant & $14.37 \%$ & $11.0 \%$ & $89.0 \%$ & 2 \\
\hline Electrical plant & $5.73 \%$ & $29.2 \%$ & $70.8 \%$ & 3 \\
\hline Control and monitoring systems & $1.13 \%$ & $43.4 \%$ & $56.6 \%$ & 5 \\
\hline $\begin{array}{l}\text { Cables, umbilicals and } \\
\text { communications, grid } \\
\text { connection }\end{array}$ & $5.30 \%$ & $31.4 \%$ & $68.6 \%$ & 4 \\
\hline Moorings and foundations & $9.18 \%$ & $51.2 \%$ & $48.8 \%$ & 1 \\
\hline Onshore equipment & $0.93 \%$ & $46.7 \%$ & $53.3 \%$ & 5 \\
\hline Other & $4.66 \%$ & $86.7 \%$ & $13.3 \%$ & 5 \\
\hline $\begin{array}{l}\text { Logistics base (e.g. } \\
\text { ports/harbours) }\end{array}$ & $1.07 \%$ & $97.5 \%$ & $2.5 \%$ & 7 \\
\hline Installation vessels & $6.66 \%$ & $36.7 \%$ & $63.3 \%$ & 6 \\
\hline Support vessels & $4.93 \%$ & $55.0 \%$ & $45.0 \%$ & 6 \\
\hline Diving & $1.60 \%$ & $83.3 \%$ & $16.7 \%$ & 8 \\
\hline Survey & $0.87 \%$ & $82.5 \%$ & $17.5 \%$ & 8 \\
\hline Onshore civil engineering & $1.40 \%$ & $90.0 \%$ & $10.0 \%$ & 8 \\
\hline Testing and precommissioning & $1.20 \%$ & $70.0 \%$ & $30.0 \%$ & 8 \\
\hline Project management & $2.53 \%$ & $77.5 \%$ & $22.5 \%$ & 8 \\
\hline
\end{tabular}


Figure 1: Cost (Emillion) per MW by year in each of the three scenarios

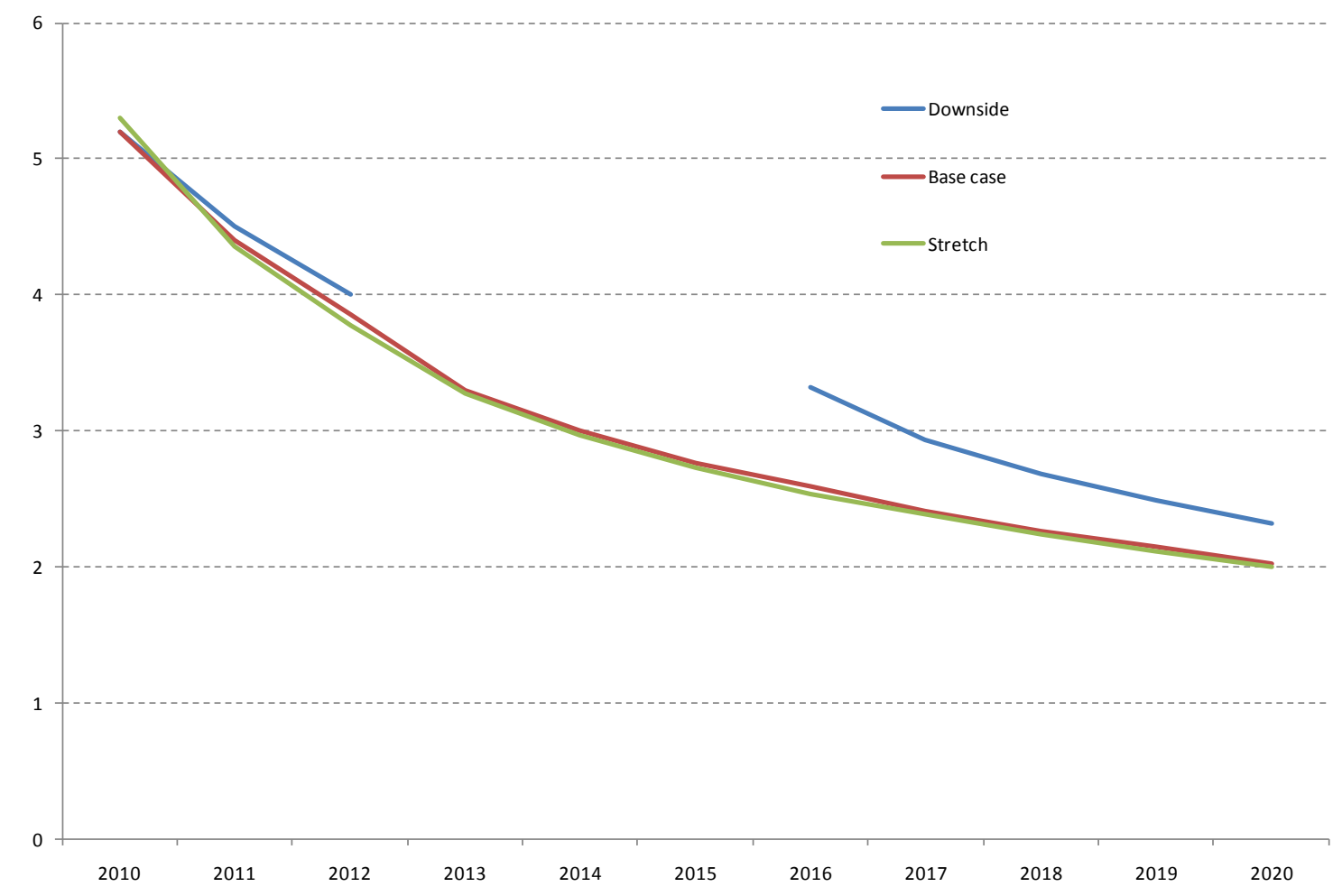


Figure 2: Employment impact of expenditures under SEI (2009) projections, IO analysis and CGE modelling, absolute difference from base year

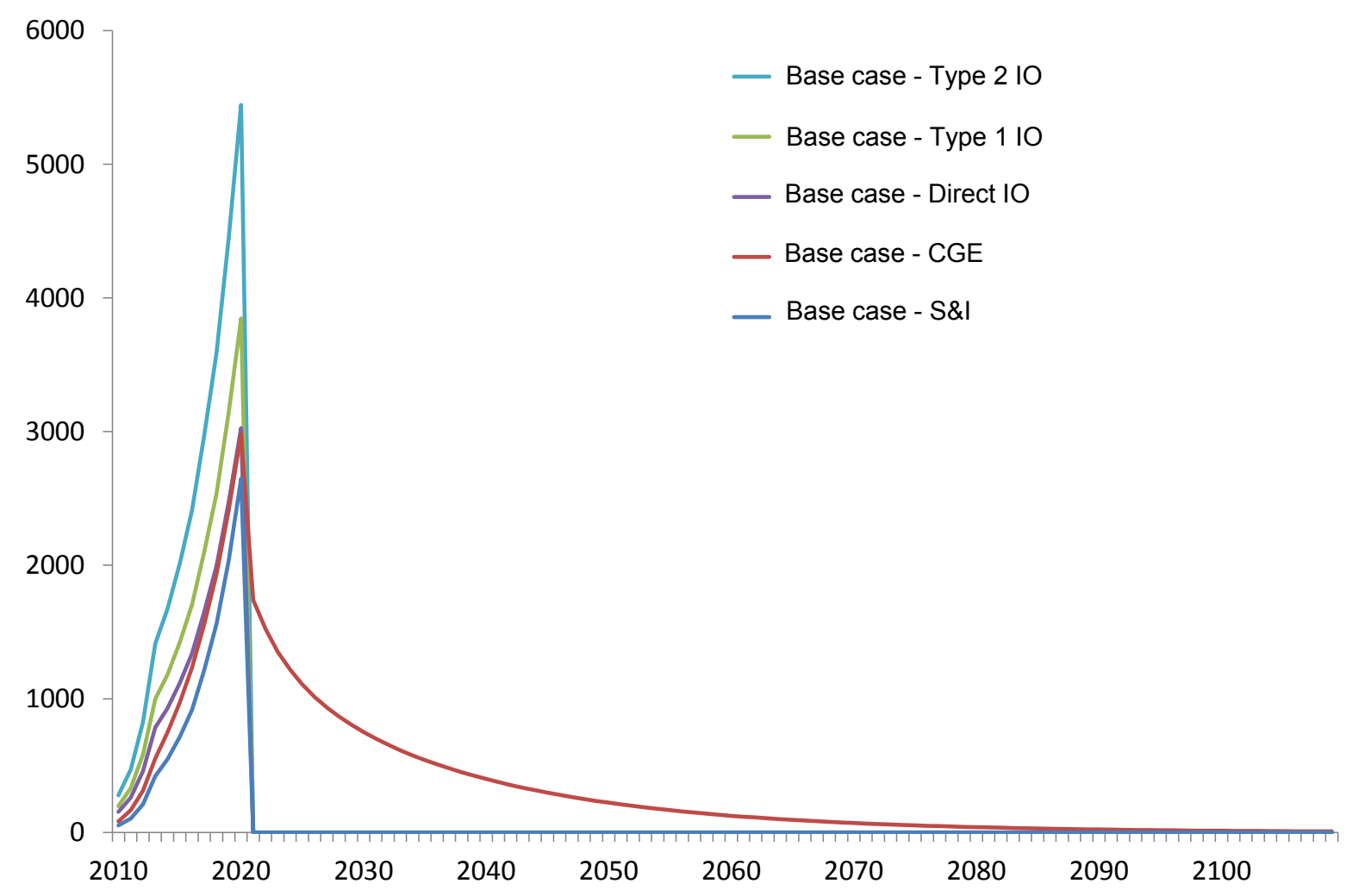


Figure 3: Sectoral employment change in Scotland in 2020, absolute figures by sector compared to base year

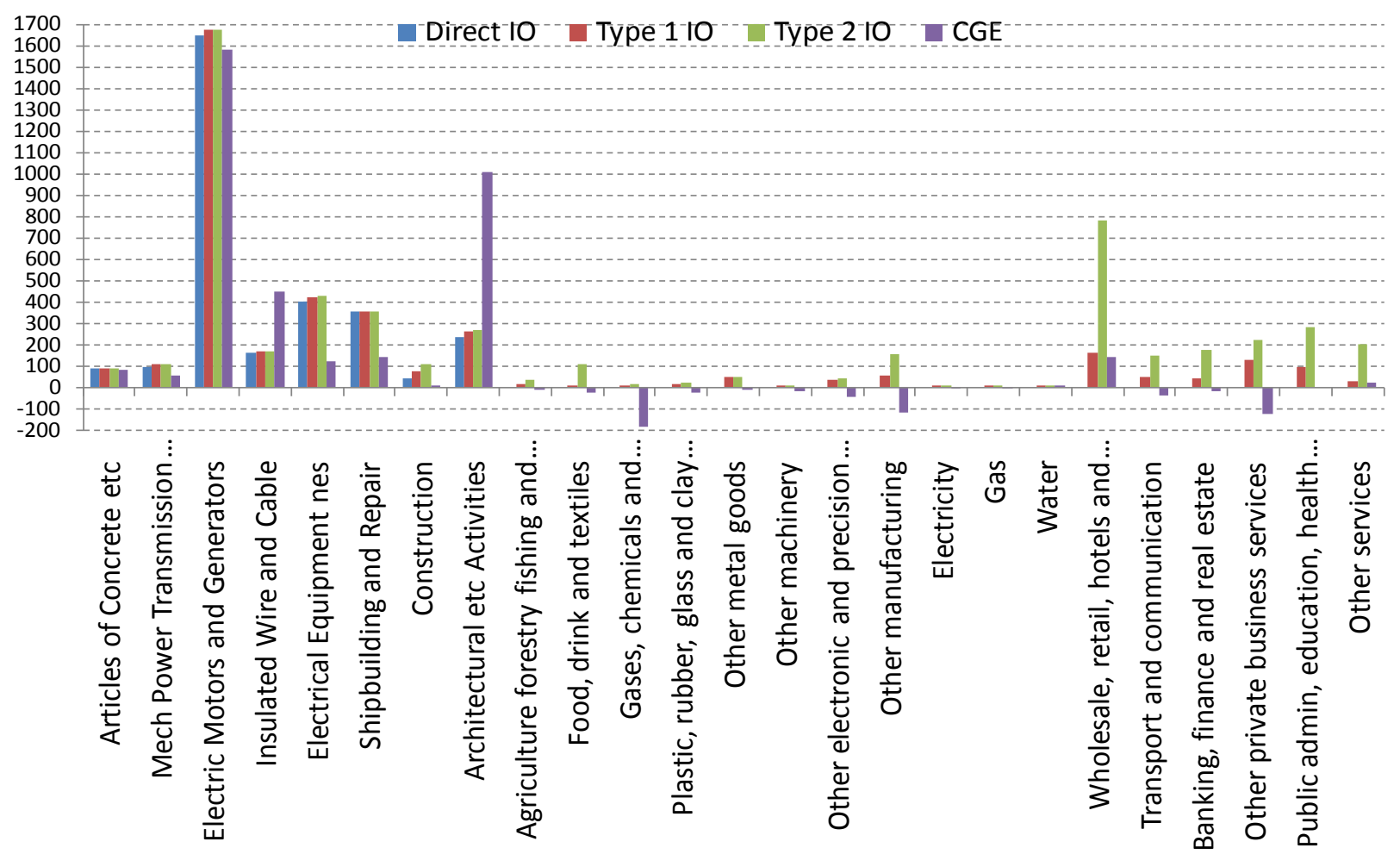


Figure 4: Real and nominal wage values in 'base case' scenario, \% changes from base

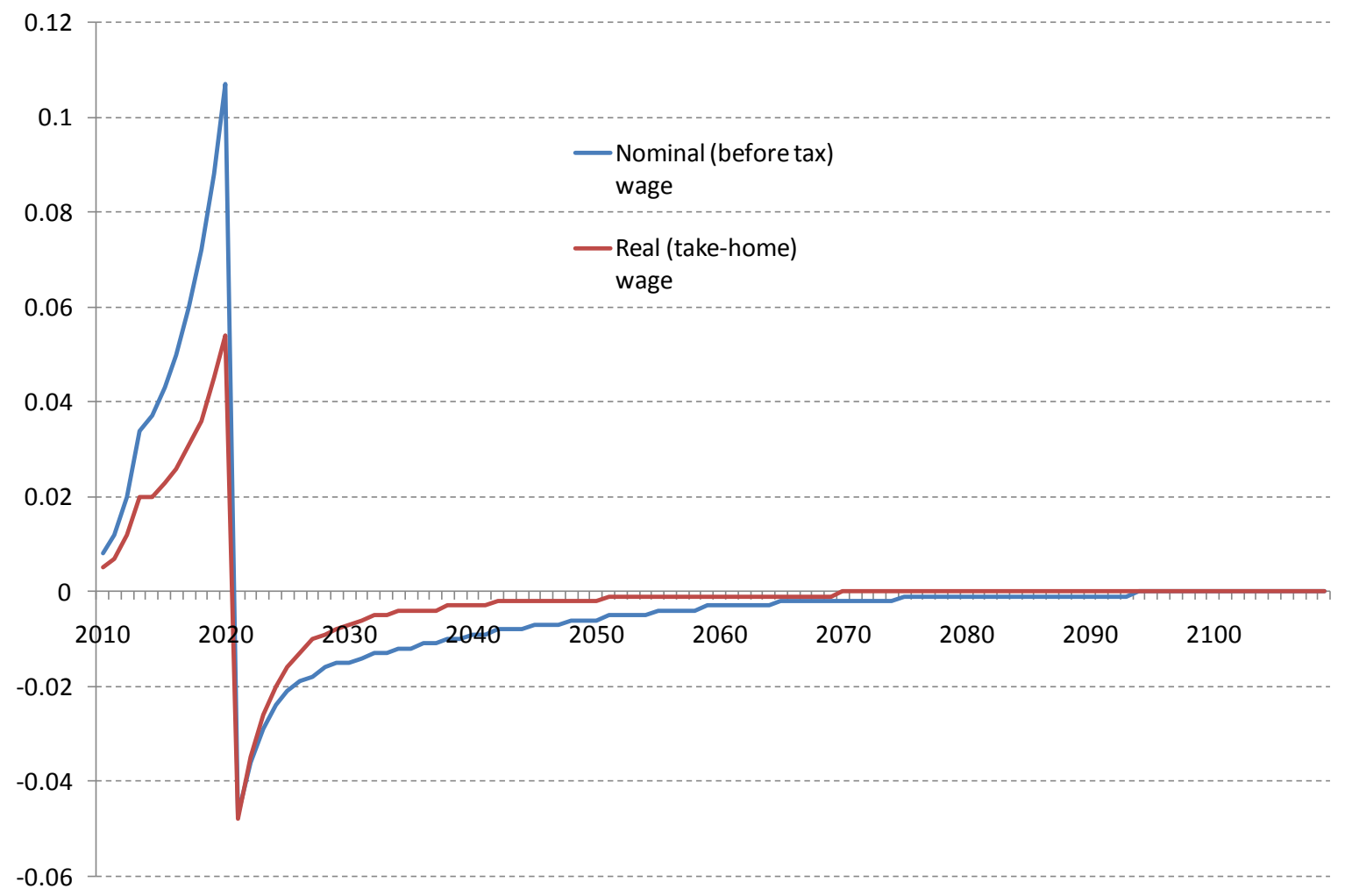


Figure 5: Capital rental rate in 'stimulated' sectors, \% change from base

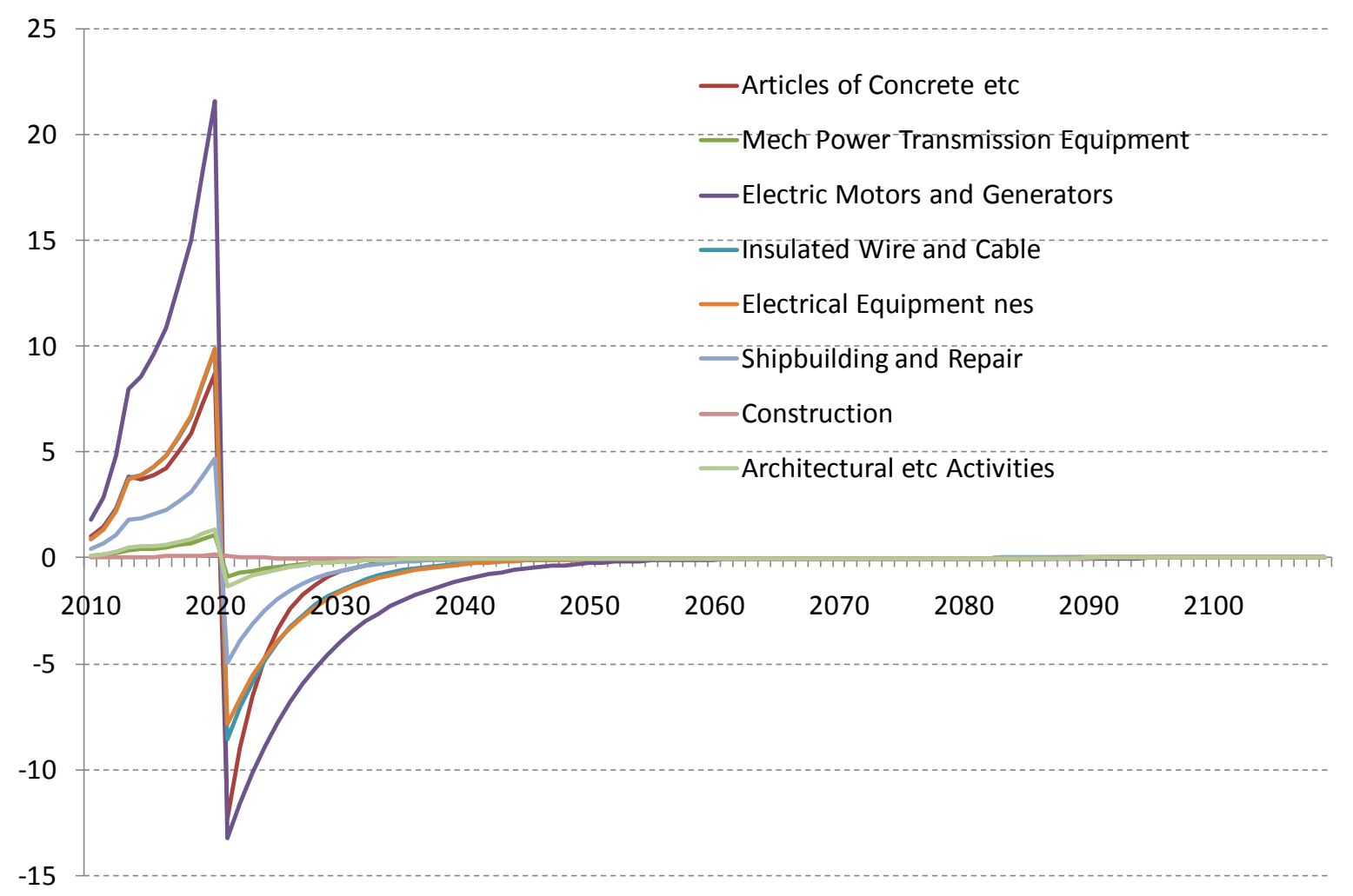


Figure 6: Capital rental rate in 'non-stimulated' sectors, \% change from base

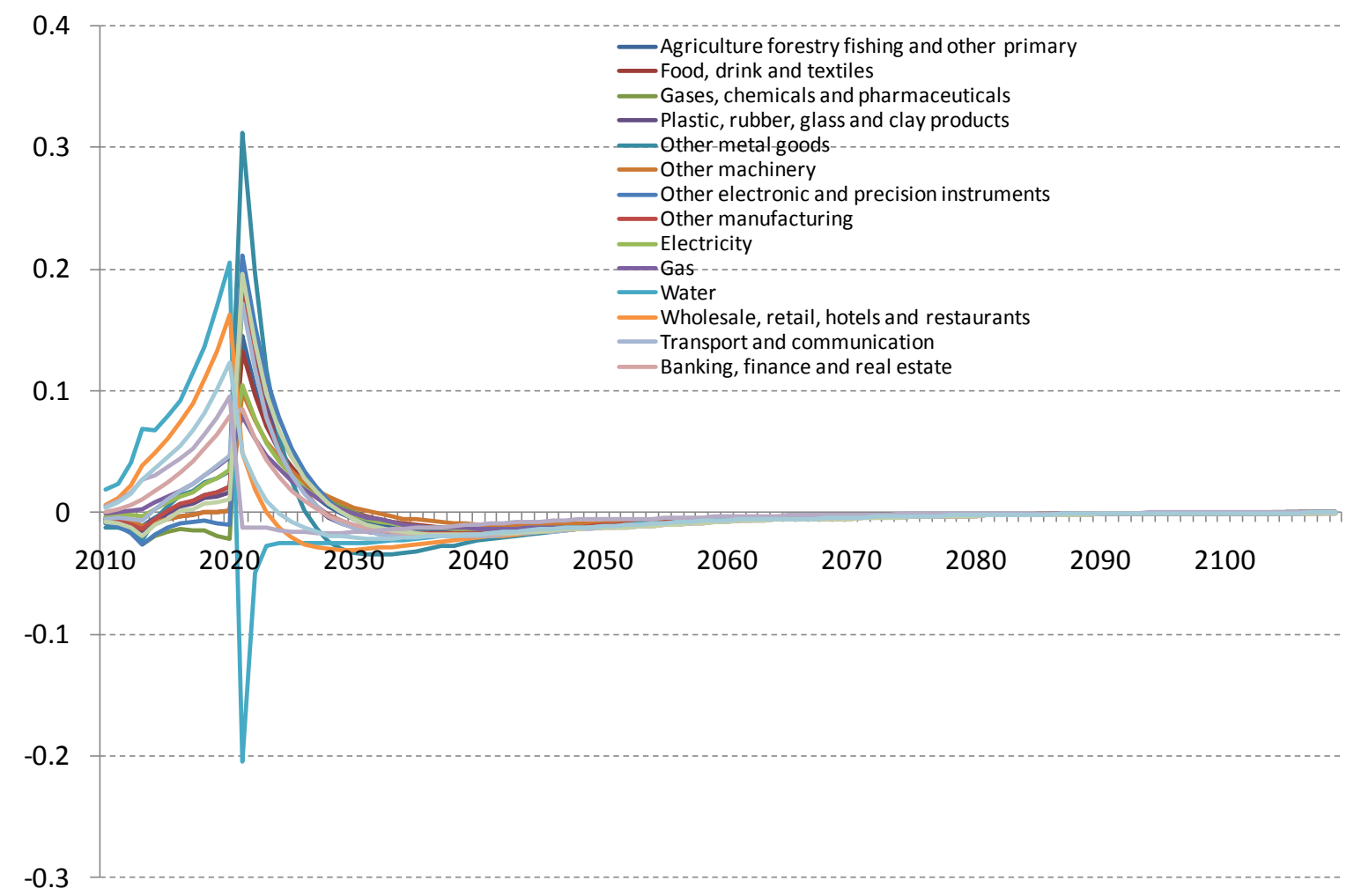


Figure 7: Output in stimulated sectors, \% change from base

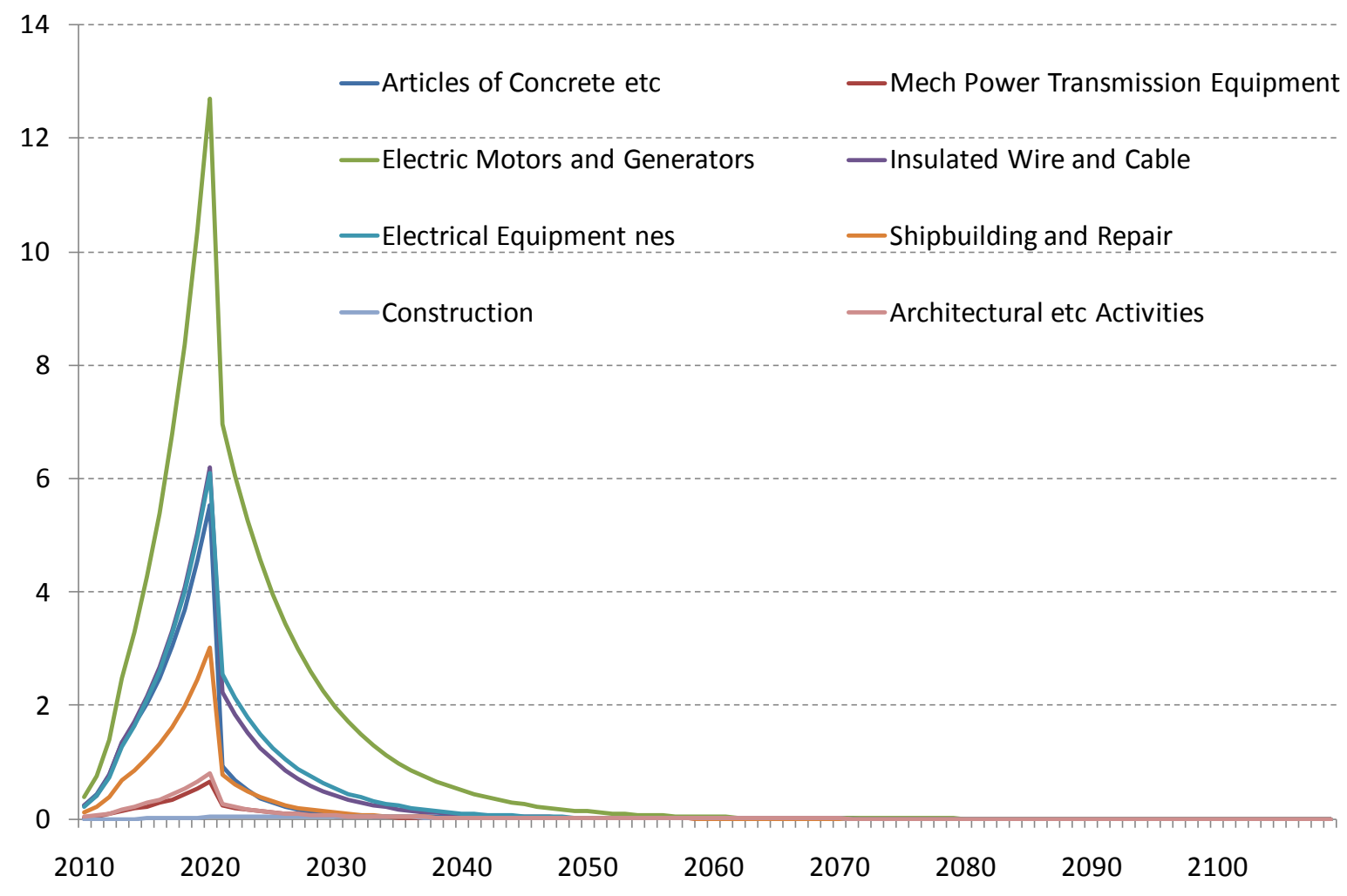


Figure 8: Output in non-stimulated sectors, \% change from base

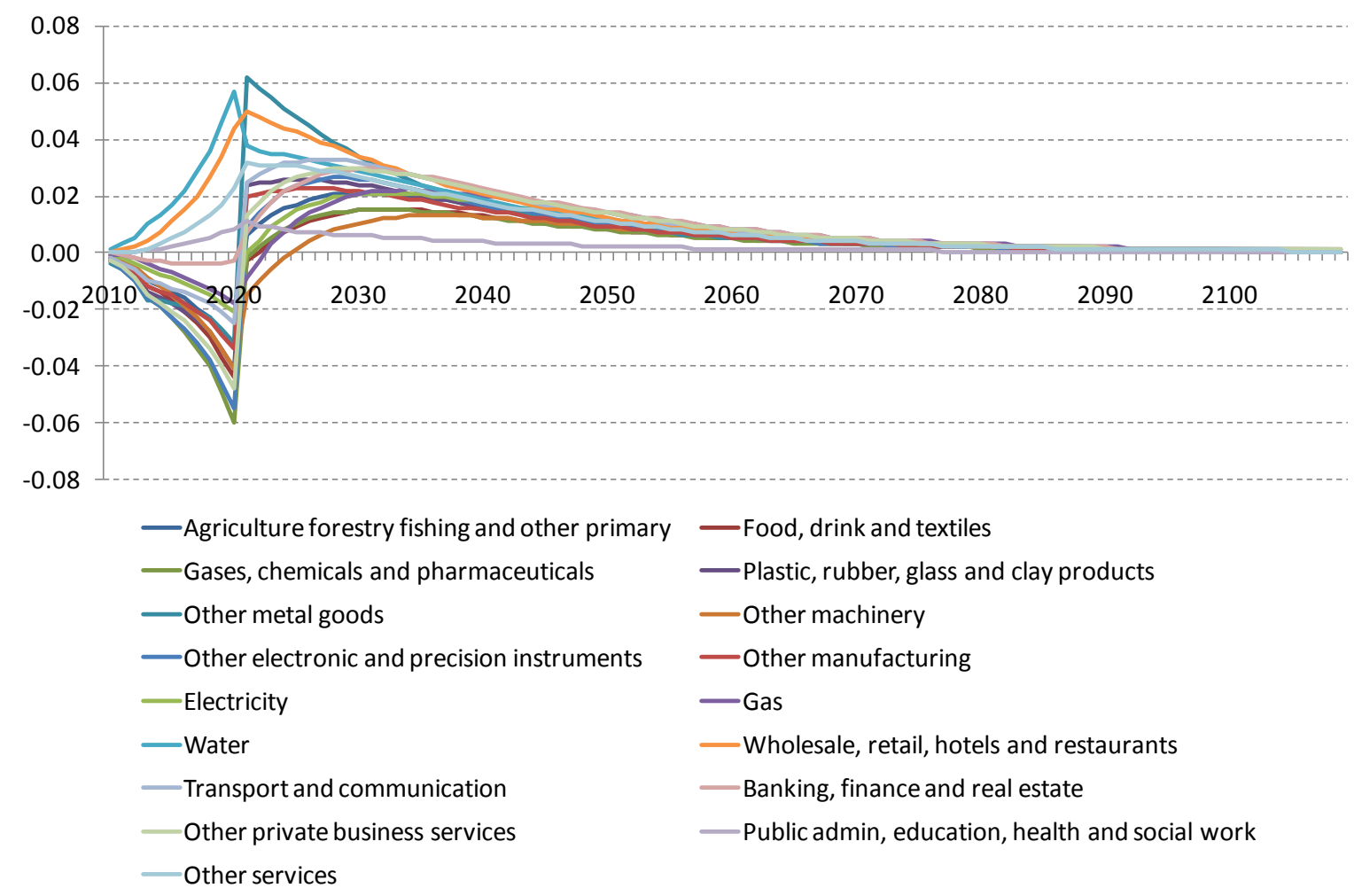


Figure 9: Discounted regional employment effects of expenditures in each sector (present value (PV) of aggregate employment divided by $P V$ of sectoral expenditures in sector i)

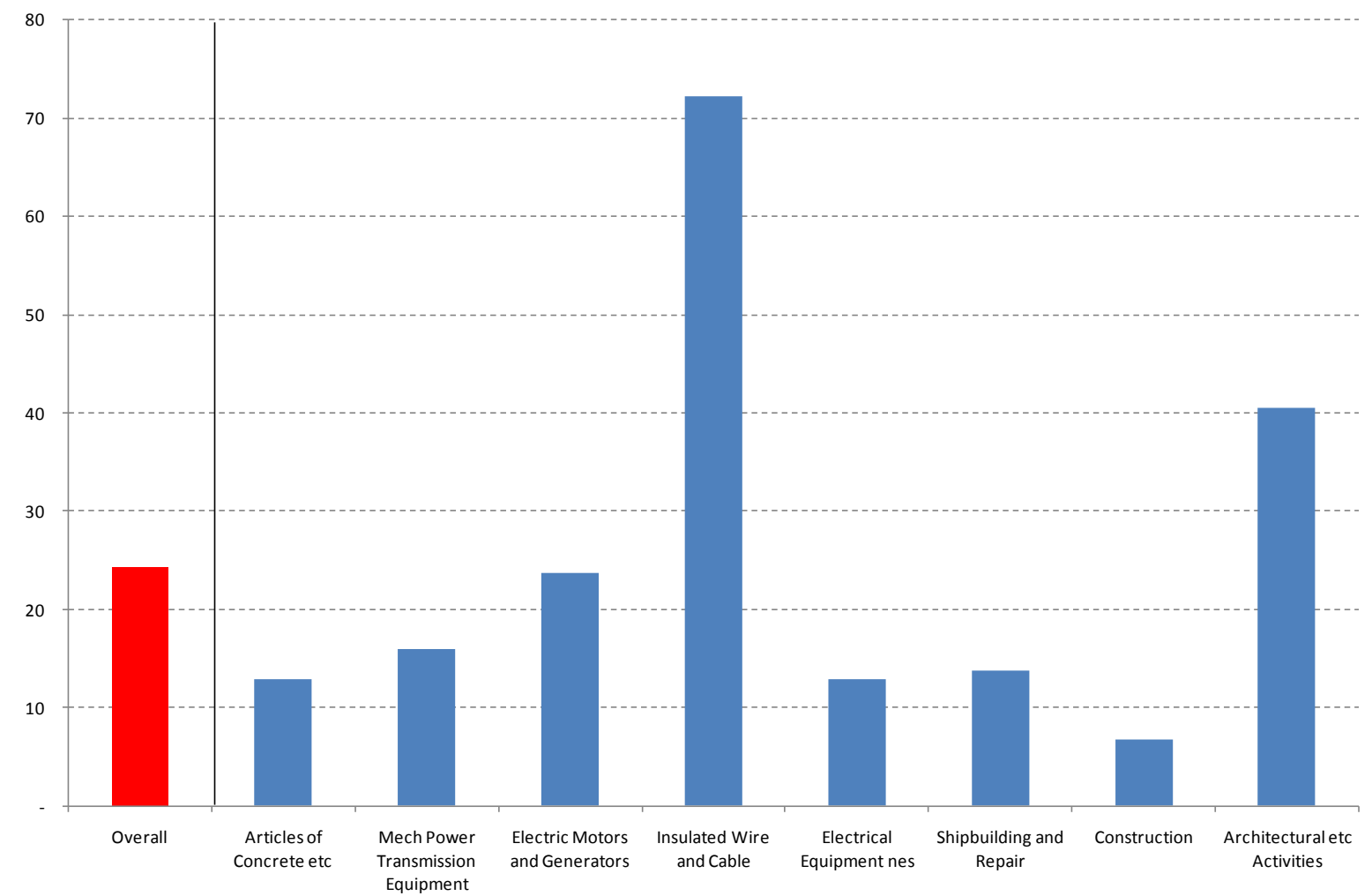


Figure 10: Additional employment for additional 1\% sourced in each category in Scotland, absolute differences from 'base case' scenario

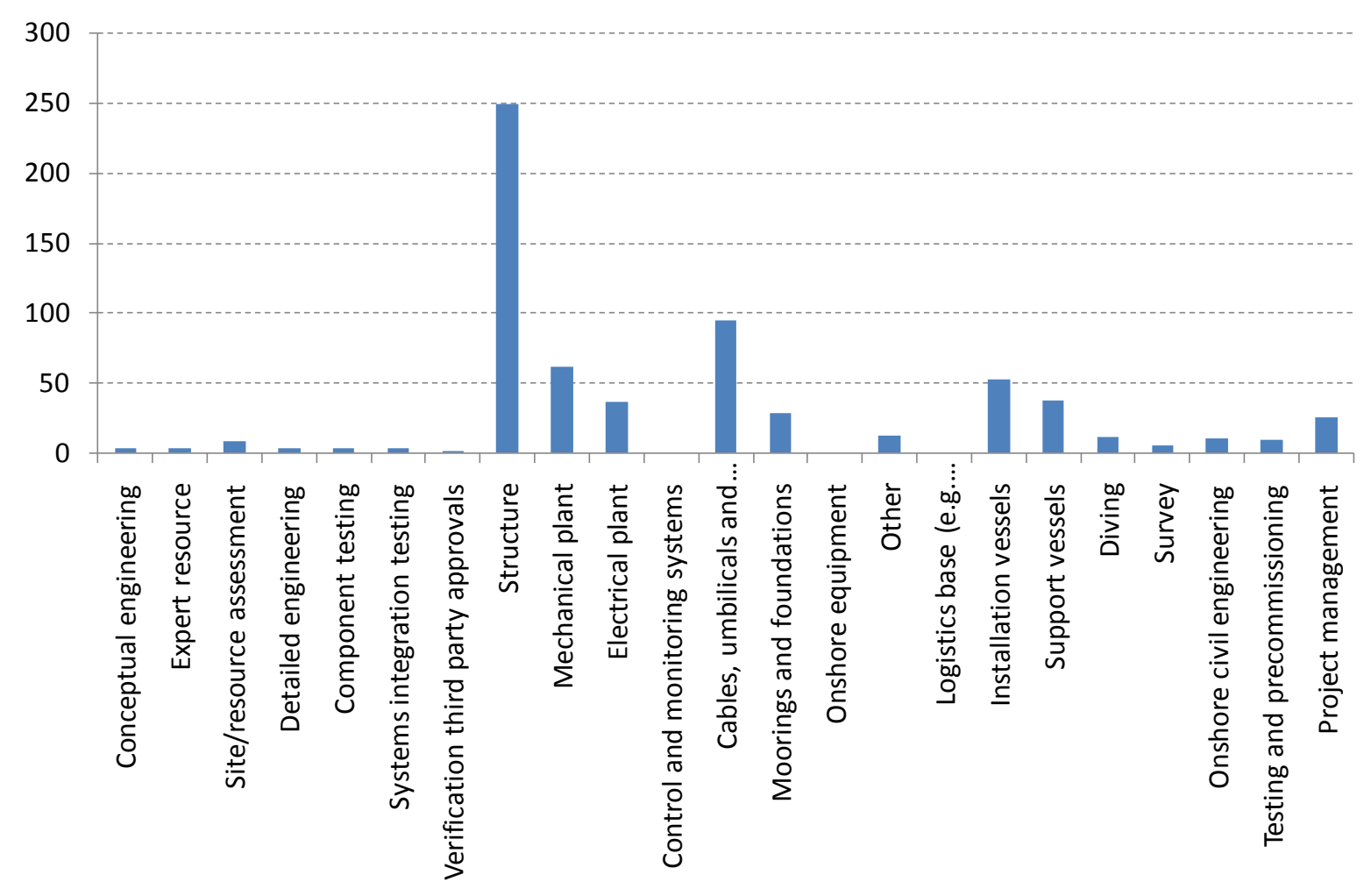


Appendix A: The sectoral breakdown of the AMOS model

\begin{tabular}{|c|c|c|}
\hline & Sectoral name & Industrial Order Classification \\
\hline 1 & Articles of Concrete etc & 53 \\
\hline 2 & Mechanical Power Transmission Equipment & 62 \\
\hline 3 & Electric Motors and Generators & 70 \\
\hline 4 & Insulated Wire and Cable & 71 \\
\hline 5 & Electrical Equipment nes & 72 \\
\hline 6 & Shipbuilding and Repair & 78 \\
\hline 7 & Construction & 88 \\
\hline 8 & Architectural etc Activities & 112 \\
\hline 9 & Agriculture, forestry, fishing and other primary & $1-7$ \\
\hline 10 & Food, drink and textiles & $8-30$ \\
\hline 11 & Gases, chemicals and pharmaceuticals & $36-45$ \\
\hline 12 & Plastic, rubber, glass and clay products & $46-52$ \\
\hline 13 & Other metal goods & $54-61$ \\
\hline 14 & Other machinery & $63-69$ \\
\hline 15 & Other electronic and precision instruments & $73-76$ \\
\hline 16 & Other manufacturing & $31-35,77,79-84$ \\
\hline 17 & Electricity & 85 \\
\hline 18 & Gas & 86 \\
\hline 19 & Water & 87 \\
\hline 20 & Wholesale, retail, hotels and restaurants & $89-92$ \\
\hline 21 & Transport and communication & $93-99$ \\
\hline 22 & Banking, finance and real estate & $100-105$ \\
\hline 23 & Other private business services & $106-111,113-114$ \\
\hline 24 & Public admin, education, health and social work & $115-118$ \\
\hline 25 & Other services & $119-123$ \\
\hline
\end{tabular}

